\title{
The dual-effects model of social control revisited: relationship satisfaction as a moderator
}

\author{
Nina Knoll ${ }^{a *}$, Silke Burkert ${ }^{\mathrm{a}}$, Urte Scholz ${ }^{\mathrm{b}}$, Jan Roigas ${ }^{\mathrm{c}}$ and Oliver Gralla ${ }^{\mathrm{d}}$ \\ ${ }^{a}$ Institute of Medical Psychology, Charité - Universitätsmedizin Berlin, Germany; ${ }^{b}$ Institute of \\ Psychology, University of Bern, Switzerland; ${ }^{\circ}$ Department of Urology, Vivantes Klinikum am \\ Urban, Berlin, Germany; ${ }^{d}$ Urologie am Ring, Cologne, Germany
}

(Received 12 December 2010; final version received 23 April 2011)

\begin{abstract}
The dual effects model of social control states that receiving social control leads to better health behavior, but also enhances distress in the control recipient. Associated findings, however, are inconsistent. In this study we investigated the role of relationship satisfaction as a moderator of associations of received spousal control with health behavior and affect. In a study with five waves of assessment spanning two weeks to one year following radical prostatectomy (RP), $N=109$ married or cohabiting prostate cancer patients repeatedly reported on their pelvic floor exercise (PFE) to control postsurgery urinary incontinence and affect as primary outcomes, on received PFE specific spousal control, relationship satisfaction, and covariates. Findings from two level hierarchical linear models with repeated assessments nested in individuals suggested significant interactions of received spousal control with relationship satisfaction predicting patients' concurrent PFE and positive affect. Patients who were happy with their relationships seemed to benefit from spousal control regarding regular PFE postsurgery while patients less satisfied with their relationships did not. In addition, the latter reported lower levels of positive affect when receiving much spousal control. Results indicate the utility of the inclusion of relationship satisfaction as a moderator of the dual effects model of social control.
\end{abstract}

Keywords: social control; health behavior; affect; couples; prostate cancer; urinary incontinence

Being part of a close and preferably happy relationship is associated with better health and a lowered mortality risk (e.g., Coyne et al., 2001). In search for mediators of this effect, researchers proposed qualitative processes that go on in social relationships, i.e., social exchange processes including social support, companionship, or health-relevant social control. These social exchange processes are proposed to have effects on health-enhancing behaviors and distress which in turn should predict physical and mental health parameters (Berkman, Glass, Brisette, \& Seeman, 2000; Rook \& Ituarte, 1999; Scholz, Knoll, Roigas, \& Gralla, 2008).

Among these social mediators of the link between social network integration and health, social control from close network members occupies a unique position (Lewis

*Corresponding author. PD Dr. Nina Knoll, Charité - Universitätsmedizin Berlin, Institute of Medical Psychology, Luisenstrasse 57, 10117 Berlin, Germany. Tel: +4930450529206; Fax: +4930450529999; Email: nina.knoll@charite.de 
\& Butterfield, 2005). Social control refers to strategies that aim at influencing or regulating another person's behavior (Lewis \& Rook, 1999), such as direct persuasion, pressure, nagging, or positive reinforcement of desired behavior. Married individuals often try to and succeed in co-regulating their partner's health behavior (Lewis \& Butterfield, 2007; Tucker, Orlando, Elliott, \& Klein, 2006). In contrast to assumptions concerning other predominantly positive social exchange processes (Benoit, Bouthillier, Moss, Rousseau, \& Brunet, 2010; Knoll, Rieckmann, \& Kienle 2007; Scholz et al., 2008), social control is proposed to be a mixed blessing (Lewis \& Rook, 1999).

In the dual-effects model of social control (Hughes \& Gove, 1981; Lewis \& Rook, 1999), the concept of social control as a mixed blessing is made explicit: it is proposed that social control produces two different effects at the same time. On the one hand, receiving social control is assumed to further recipients' health behavior, because it instills or amplifies in recipients a sense of obligation to promote health for the benefit of their social network. At the same time, social control is suggested to enhance recipients' distress, as it limits their freedom of choice (e.g., Lewis \& Rook, 1999).

Empirical evidence for the dual-effects model of social control is mixed. Some studies find social control related with better health behavior (Lewis \& Butterfield, 2007; Lewis \& Rook, 1999; Tucker, 2002; Umberson, 1992); however, there are also many examples for reactance in response to social control (Stephens, Rook, Franks, Khan, \& Iida, 2010; Thorpe, Lewis, \& Sterba, 2008). For instance, Helgeson, Novak, Lepore, and Eton (2004) investigated effects of spousal control on health-related behaviors and indicators of distress in a sample of prostate-cancer patients following treatment. Authors found received social control concurrently related with more health-compromising behaviors.

Relationships between received social control and indicators of distress in control recipients are also inconsistent. In Helgeson et al.'s (2004) study with prostate-cancer patients, patients reported higher levels of depressive symptoms when their spouses exerted much control over their health-relevant behavior. A number of studies also find distress indicators positively correlated with received social control (Lewis \& Rook, 1999; Thorpe et al., 2008), while others do not (Rook, Thuras, \& Lewis, 1990). One way to resolve such inconsistent findings is by assuming moderators that may further qualify both relationships assumed by the dual-effects model.

In their contextual model, Okun, Huff, August, and Rook (2007) suggest relationship quality within the control dyad as a possible moderator of controloutcome relationships. Specifically, they assume that receiving social control in unhappy relationships is associated with more hiding of risky behaviors by the recipient. Authors found support for the contextual model in a sample of college students in dating relationships. In a sample of older individuals, Tucker (2002) found direct social control from the network related with more hiding of unhealthy behaviors when control recipients rated their relationship with the control provider as less satisfactory. Tucker (2002) also reported that relationship satisfaction moderated the association between received direct social control and negative affect. Persons receiving direct control from a network partner with whom they were in a happy relationship reported less negative affect than persons receiving control within an unhappy relationship. 
In this paper, we investigate relationship satisfaction as a potential moderator of relations of spousal social control with health-enhancing behavior and indicators of distress in prostate-cancer patients recovering from incontinence following treatment.

\section{Adaptation to incontinence following radical prostatectomy (RP)}

With about 60,000 patients diagnosed per year, prostate carcinoma is now the most common cancer in German men (Robert Koch-Institute [RKI] and Society of Epidemiologic Cancer Registers in Germany, 2010). The risk for prostate cancer increases with chronological age. In Germany, the average age at diagnosis is 69 years (RKI and Society of Epidemiologic Cancer Registers in Germany, 2010). Depending on patients' age, health-status, and preference, RP is one of the most opted-for treatments by patients with a localized prostate carcinoma and a life expectancy of 10 years or more (European Association of Urology [EAU], 2010). RP refers to the removal of the entire prostate gland between urethra and bladder, with bilateral resection of seminal vesicles. Although RP has good oncologic results, postoperative morbidities such as urinary incontinence and erectile dysfunctions are frequent (Stanford et al., 2000).

In early phases following the operation, both patients and partners have to adapt to patients' urinary incontinence with initial limitations of range of daily activity, issues of shame, and uncertainty as to its development and duration (Resendes \& McCorkle, 2006). During this time, patients often require help from their partners in managing increased loads of laundry, taking over daily chores, transportation of pads, or more detailed planning of social activities (Knoll, Burkert, Luszczynska, Roigas, \& Gralla, in press). As partners are highly involved in patients' rehabilitation from surgery, not only supportive (Knoll, Burkert, Kramer, Roigas, \& Gralla, 2009), but also controlling interactions have been documented to take place between partners (Helgeson et al., 2004). Spousal control of patients' behavior following surgery may include positive reinforcement of, but also pressure to engage in active forms of coping with incontinence (e.g., performing pelvic-floor exercise [PFE], improve management of pads, or taking up again chores and errands).

While incontinence persists, patients' burden due to incontinence is usually higher than burden associated with postoperative erectile dysfunctions (Resendes \& McCorkle, 2006). Moreover, about $1015 \%$ of patients remain incontinent beyond 24 months following RP (Stanford et al., 2000). One of the few means to directly and actively control incontinence is regular exercise of the pelvic floor. Following surgery, patients are taught to use their pelvic floor as a sphincter to prevent leakage. Implementation and maintenance of regular PFE by patients served as our target health-enhancing behavior. At this point, there are no general evidencebased recommendations concerning exercise frequency and intensity. In the present study, patients were encouraged to perform PFE three times daily for 10 minutes by the urology department's physiotherapy staff and a written brochure. As PFE may only help to relieve incontinence over the course of several months (Filocamo et al., 2005), patients were encouraged to exercise as long as incontinence persisted. 


\section{Hypotheses}

In the present study, we follow Tucker (2002) and investigate the role of relationship satisfaction as a moderator of the dual effects of social control in a one-year longitudinal study with married or cohabiting prostate-cancer patients instructed to perform regular PFE to control urinary incontinence following RP. We suggest that in prostate-cancer patients rating their relationships as satisfactory, the receipt of spousal control regarding PFE should be more strongly related with PFE than in patients less satisfied with their relationships. Moreover, we propose that overall higher relationship satisfaction may buffer some of the detrimental effects of social control on control recipients' mood. Specifically, we assumed that for prostate-cancer patients who were very satisfied with their relationships, receipt of spousal control for regular PFE would be less strongly associated with positive and negative affect than for patients who reported to be less satisfied with their relationships. For the latter we expected significant positive relations of spousal control receipt with negative affect and significant negative relations with positive affect. We tested concurrent associations between predictors and outcomes for the overall time-frame of this study which included five assessments, ranging from two weeks until one year following surgery. We do not specify hypotheses with regard to expected changes in the associations over time.

\section{Method}

\section{Participants}

Data were collected from patients participating in a couple intervention study on the implementation of regular PFE following RP (see below; Burkert, Scholz, Gralla, \& Knoll, forthcoming ${ }^{1}$ ). Exclusion criteria were not having a partner or the partner's refusal or inability to fully participate in the study (as indicated prior to inclusion into the study) and insufficient comprehension of the German language. Although only data from patients were analyzed, the sampling process reflects inclusion of couples in this study. Of 308 patients scheduled for RP, 130 patients or partners could not be asked due to logistic reasons or did not consent; 16 patients did not receive their scheduled surgery or were not in a relationship; 17 patients or partners withdrew consent; and 34 patients or partners were only partly eligible for participation, did not provide any data, or provided data on measurement points not included in this study. As inclusion in the study was not limited to heterosexual couples, the initial sample included two same-sex couples. In light of evidence on different relationship processes in same-sex couples (Kurdek, 2004), data from patients of these two couples were not included in the present analyses. Data from 109 patients were analyzed.

Patients' mean age was 62.44 years (standard deviation $[\mathrm{SD}]=6.07$ ), most patients were married $(n=96 ; 88.07 \%)$, nine patients reported living with their partner $(8.26 \%)$, four patients $(3.67 \%$ ) did not report their exact marital/relationship status, but had indicated to be in a relationship upon inclusion in the study. Most patients $(89.99 \%)$ had children. Regarding education, $33.95 \%$ of patients reported 9 10 years of schooling, $59.63 \%$ reported 1213 years of schooling. One patient reported less than nine years of schooling, the remaining six patients $(5.50 \%)$ did not specify educational level. About half of the patients $(53.21 \%)$ were retired. All 
patients underwent minimally invasive laparoscopic RP. In about half of the surgeries (45.87\%), nerves that enable erectile functions could be spared. Patients' tumors varied in size (as denoted by "T" =tumor; T1: 2.8\%; T2: 76.6\%; T3: 20.6\%), however, none had spread to lymph nodes (as denoted by " $\mathrm{N}$ " = nodes; N0: $100 \%$ ) or more distant sites of the body (as denoted by "M" = metastases; M0: 100\%). Two weeks postsurgery, among patients who did not wear a catheter at the time $(n=86)$, only one patient reported no incontinence.

Of $N=109$ patients, 81 patients provided full data (74.3\%), 16 patients $(14.7 \%)$ missed one assessment, four patients $(3.7 \%)$ missed three assessments, and eight patients $(7.3 \%)$ did not complete more than two assessments. Patients who provided full data were more likely to have children (as reported by partners; Spearman $r h o=.20, p<.05$ ) and had a longer relationship duration (Spearman rho $=.17$, $p<.08$ ).

\section{Procedure}

Upon patients' admission to the department of urology of a German university medical centre, they were approached, informed about the study, and invited for participation. A first measurement took place upon inclusion into the study, one day prior to surgery. All patients and their partners were part of a randomized controlled trial in which they were assigned to one of four groups of a couple-intervention. The one-time intervention session took place upon patients' discharge from the hospital. In the intervention, patients planned either individually or together with their partners how to perform regular PFE or comply with a healthy diet $(2 \times 2$ design). When patients were assigned to one of the two individual planning groups, still both patients and partners arrived in the lab together. Patients then participated in the intervention while their partners were escorted to a different room and asked to complete another questionnaire (further details on the intervention are available from the authors upon request; Burkert et al., forthcoming ${ }^{1}$ ). Participants were asked to provide further data at two weeks, one month, three months, six, and 12 months postsurgery. They were sent questionnaires via mail and instructed to complete materials. The study was approved by the institutional review board.

In this study, we concentrated on patients' reports of predictors and outcomes. While a dyadic approach to the investigation of health-related correlates of spousal control would be superior, our study did not allow for a full reciprocal dyadic assessment of predictors and outcomes as by definition, patients were the only part of the dyad afflicted with incontinence. Relatedly, in our design we could not investigate effects of gender or gender role as all patients were male. Moreover, because urinary incontinence sets in following surgery, it was decided not to include the pre-surgery measurement in the present analyses.

\section{Measures}

Pelvic-floor exercise (PFE) was measured by self-report. Patients indicated on how many days during the past week and for how many times a day they had engaged in PFE. Moreover, they were asked how much time they had usually spent exercising per unit. Frequencies and average duration per unit were multiplied to obtain a 
measure of weighted duration of PFE during the past week. The mean retestcorrelation between adjacent assessments of PFE was $r_{\mathrm{tt}}=.45$.

Patient-reported affect was assessed using the Positive and Negative Affect Schedule (PANAS; Watson, Clark, \& Tellegen, 1988) in its German translation (Krohne, Egloff, Kohlmann, \& Tausch, 1996). The positive and negative affect scales consisted of 10 adjectives each. Participants were asked to rate their own affect on the respective day by indicating answers on a four-point scale for each adjective. Endorsements ranged from not at all (1) to very much (4). Internal consistency of positive affect ranged between Cronbach's $\alpha=.87$ and $\alpha=.91$. Internal consistency of negative affect ranged between Cronbach's $\alpha=.83$ and $\alpha=.90$.

Patients' received spousal control regarding PFE was assessed with one item adapted from Lewis and Rook (1999). "How often did your partner try to influence you to regularly perform pelvic-floor exercise?" Patients endorsed the frequency of perceived control from the spouse during the past seven days on a four-point scale ranging from "never" (1) to "at least once a day" (4). Stability of received spousal control was moderate with a mean retest-correlation of $r_{\mathrm{tt}}=.54$.

Patient-reported relationship satisfaction was measured using a single item by Hahlweg (1996): "How happy is your relationship at this point in time?" This item was rated on a six-point Likert-type scale ranging from "very unhappy" (1) to "very happy" (6). This global appraisal of relationship satisfaction has been documented to have good validity. Hahlweg reported a correlation of $r=.78$ of the 1 -item rating with the general score of the 30 -item inventory assessing relationship functioning (Relationship Questionnaire; Hahlweg, 1996). Hahlweg's Relationship Questionnaire in turn is based on different widely employed relationship quality measures (e.g., Dyadic Adjustment Scale; Spanier, 1976) and has been documented to be reliable and valid (Hahlweg, Klann, \& Hank, 1992). The mean retest correlation of the single item used was $r_{\mathrm{tt}}=.66$.

Patient-reported incontinence was assessed using the burden by incontinence item from the German short form of the International Consultation of Incontinence Questionnaire (ICIQ-SF; Karantanis, Fynes, Moore, \& Stanton, 2004): "How limited is your life due to the involuntary leaking of urine?"' Patients were asked to respond on an 11-point scale ranging from "not at all" $(0)$ to "strongly" $(10)$. A mean retest correlation amounted to $r_{\mathrm{tt}}=.74$. Existence of an indwelling catheter was also measured via self-report. Patients were asked to report whether or not they were currently wearing an indwelling catheter $n=23$ patients $(21.10 \%)$ wore a catheter at two-weeks postsurgery and $n=8$ patients $(7.34 \%)$ wore a catheter at one month postsurgery.

Table 1 presents information on descriptive statistics of the central variables.

\section{Analyses}

To account for missing data, we employed multiple imputation (MI) (NORM 2.03; Schafer, 1999) including all central variables as well as the missing-related variables, i.e., children (partner-reports) and relationship duration (as reported by patients and partners) into the imputation model. MI accounts for missing-data uncertainty by generating multiple values for respective points of missing data, creating multiple data-sets, and introducing between-imputation variance. Each of these data-sets was analyzed separately. Results were integrated in a last step using PASW 18-Multiple 
Imputation to obtain overall estimates and standard errors. For the present study, five datasets were generated and analyzed.

All analyses were two-level models with five repeated assessments nested in patients, analyzed with PASW 18 Mixed Models. Patient-reported PFE and positive and negative affect were the dependent variables in central models. Because measurement occasions were spaced apart unequally, i.e., inter-measurement intervals ranged between two weeks and six months, we did not test lagged predictions. We used a maximum likelihood approach and imposed a first-order autoregressive error covariance structure.

To examine our hypotheses three central models, i.e., one for each dependent variable, were tested. The following time-varying predictors were included in level-1 models: a linear time trend, patient's burden by incontinence, existence of an indwelling catheter, patients' ratings of received spousal control regarding regular PFE, patients' ratings of relationship satisfaction, and the interaction of the latter two. We kept patients who still wore a catheter at the first $(21.10 \%)$ and second $(7.34 \%)$ measurement points in the analyses to avoid creating additional bias. Except for the catheter variable, which was coded 1 for "catheter present" and 0 for "no catheter present" and the linear time trend, all other predictors were centered around their grand means. TIME was centered at the first measurement point included in the analyses and coded in weeks.

Level-1 model:

$$
\begin{aligned}
& Y_{i j}=\pi_{0 i}+\pi_{1 i} \operatorname{TIME}_{j}+\pi_{2 i} \text { incontinence }_{i j}+\pi_{3 i} \text { catheter }_{i j} \\
& +\pi_{4 i} \text { patient's relationship satisfaction }_{i j} \\
& +\pi_{5 i} \text { patient's received spousal control } l_{i j} \\
& +\pi_{6 i} \text { patient's relationship statisfaction } * \text { received spousal }+\varepsilon_{i j}
\end{aligned}
$$

Level-2 models did not include further covariates, random effects of the level-1 predictors were tested.

Sample level-2 model:

$$
\pi_{0 i}=\gamma_{00}+\zeta_{0 i}
$$

To follow-up significant interaction terms, plot them, and test simple slopes and regions of significance, we used a tool provided by Preacher, Curran, and Bauer (2006). A pseudo $R^{2}$ was calculated for central models, using an unconditional means version and a random-intercept version of the full models containing all predictors.

\section{Results}

\section{Preliminary analyses}

As participating patients and their partners were part of a randomized controlled trial (further details on the intervention are available from the authors upon request, Burkert et al., forthcoming ${ }^{1}$ ), we investigated possible involvement of the intervention in our central models first. Intervention-group assignments were dummy coded and tested as main effects on PFE and affect variables. Also, intervention-factors' interactions with patient-reported frequency of spousal control regarding PFE and patients' relationship satisfaction were investigated. As inclusion of intervention 
Table 1. Descriptive Statistics for Central Variables

\begin{tabular}{|c|c|c|c|c|c|c|c|c|}
\hline & & $\begin{array}{c}2 \text { weeks } \\
\text { postsurgery }\end{array}$ & $\begin{array}{c}1 \text { month } \\
\text { poststurgery }\end{array}$ & $\begin{array}{l}3 \text { months } \\
\text { postsurgery }\end{array}$ & $\begin{array}{l}6 \text { months } \\
\text { postsurgery }\end{array}$ & $\begin{array}{l}12 \text { months } \\
\text { postsurgery }\end{array}$ & Intercept & TIME \\
\hline & Range & & & $M(S D)$ & & & $\begin{array}{c}\text { Estimate } \\
(S E)\end{array}$ & Estimate $(S E)$ \\
\hline $\begin{array}{l}\text { Weekly pelvic floor } \\
\text { exercise (minutes) }\end{array}$ & $(0-750)$ & $\begin{array}{c}169.07 \\
(183.72-204.71)\end{array}$ & $\begin{array}{c}203.41 \\
(138.70-157.47)\end{array}$ & $\begin{array}{c}192.44 \\
(134.37-143.18)\end{array}$ & $\begin{array}{c}135.86 \\
(123.84-129.86)\end{array}$ & $\begin{array}{c}100.17 \\
(130.14-136.39)\end{array}$ & $\begin{array}{c}188.70^{* * *} \\
(12.689)\end{array}$ & $\begin{array}{l}-1.78^{* * *} \\
(.376)\end{array}$ \\
\hline Positive affect & $(1-4)$ & $\begin{array}{c}2.32 \\
(.56-.58)\end{array}$ & $\begin{array}{r}2.34 \\
(.56-.59)\end{array}$ & $\begin{array}{c}2.48 \\
(.57-.60)\end{array}$ & $\begin{array}{c}2.39 \\
(.60-.63)\end{array}$ & $\begin{array}{c}2.50 \\
(.61-.66)\end{array}$ & $\begin{array}{l}2.35^{* * *} \\
(.050)\end{array}$ & $\begin{array}{c}.003^{*} \\
(.001)\end{array}$ \\
\hline Negative affect & $(1-4)$ & $\begin{array}{c}1.33 \\
(.33-.34)\end{array}$ & $\begin{array}{r}1.31 \\
(.34-.35)\end{array}$ & $\begin{array}{c}1.21 \\
(.31-.32)\end{array}$ & $\begin{array}{c}1.21 \\
(.30-.32)\end{array}$ & $\begin{array}{c}1.24 \\
(.34-.37)\end{array}$ & $\begin{array}{l}1.29^{* * *} \\
(.028)\end{array}$ & $\begin{array}{l}-.001^{*} \\
(.001)\end{array}$ \\
\hline $\begin{array}{l}\text { Received spousal } \\
\text { control }\end{array}$ & $(1-4)$ & $\begin{array}{c}2.24 \\
(1.21-1.30)\end{array}$ & $\begin{array}{c}2.19 \\
(1.22-1.24)\end{array}$ & $\begin{array}{c}2.05 \\
(1.10-1.12)\end{array}$ & $\begin{array}{c}2.02 \\
(1.12-1.14)\end{array}$ & $\begin{array}{c}1.77 \\
(1.01-1.06)\end{array}$ & $\begin{array}{l}2.21^{* * * *} \\
(.094)\end{array}$ & $\begin{array}{l}-.009^{* *} \\
(.003)\end{array}$ \\
\hline $\begin{array}{l}\text { Relationship } \\
\text { satisfaction }\end{array}$ & $(1-6)$ & $\begin{array}{c}5.13 \\
(.74-.78)\end{array}$ & $\begin{array}{r}5.23 \\
(.78-.83)\end{array}$ & $\begin{array}{c}5.13 \\
(.80-.82)\end{array}$ & $\begin{array}{c}5.04 \\
(.86-.89)\end{array}$ & $\begin{array}{c}4.97 \\
(.92-1.00)\end{array}$ & $\begin{array}{l}5.17^{* * *} \\
(.073)\end{array}$ & $\begin{array}{l}-.004^{*} \\
(.002)\end{array}$ \\
\hline $\begin{array}{l}\text { Burden by } \\
\text { incontinence }\end{array}$ & $(0-10)$ & $\begin{array}{c}6.85 \\
(2.89-3.21)\end{array}$ & $\begin{array}{c}6.82 \\
(2.97-3.09)\end{array}$ & $\begin{array}{c}4.87 \\
(3.38-3.44)\end{array}$ & $\begin{array}{c}3.35 \\
(3.02-3.24)\end{array}$ & $\begin{array}{c}2.72 \\
(2.86-3.02)\end{array}$ & $\begin{array}{l}6.28^{* * *} \\
(.294)\end{array}$ & $\begin{array}{l}-.071^{* * * *} \\
(.006)\end{array}$ \\
\hline
\end{tabular}

Note. $N=109 .{ }^{*} p<.05,{ }^{* *} p<.01,{ }^{* * *} p<.001$. Pooled grand means $(M)$ from 5 imputed data sets. Ranges of standard deviations $(S D$ s) from 5 imputed data sets. Summary statistics for change in central variables come from 2 level random intercept models with time points nested in individuals. SE: standard error, findings based on 5 imputed data sets. 
factors into the central models did not change our findings, respective analyses and intervention factors are not further reported here. Instead, intervention groups were collapsed and data from $N=109$ patients were analyzed.

\section{Descriptive results}

We tested changes in our central variables by means of two-level random intercept models with a linear time trend on level-1 (see Table 1). While on a mean level, PFE appeared to increase between two weeks and one month following surgery and then decrease again until one year postsurgery, a linear time trend seemed to fit the data better than higher-order polynomials. Positive affect increased slightly between two weeks and one year postsurgery, whereas negative affect decreased during this time.

All other central predictors and covariates in this study, i.e., patient-reported received spousal control for PFE, patient-reported relationship satisfaction, and patient-reported burden by incontinence decreased within one year following surgery (see Table 1).

\section{Central models: relationship satisfaction moderates relationships of spousal control on $P F E$ and affect}

As stated above, central models included a linear time trend, all time-varying predictors, and the interaction between received spousal control and relationship satisfaction, all reported by patients. Where feasible in terms of model convergence, we examined level-1 predictors' random effects.

The first model tested our hypothesis regarding patients' PFE (see Table 2, Model 1). As assumed, the linear interaction between patient-reported spousal control and patient-reported relationship satisfaction predicted significant amounts of PFE variance. The plotted interaction (see Figure 1, Panel A) indicated that patients who were very satisfied with their relationships (upper $20 \%$ percentiles of the distribution), reported more PFE when they also reported higher PFE-specific received control from their partners [high relationship satisfaction: simple slope (standard error $[\mathrm{SE}])=17.72(7.39), z=2.40, p=.017$; significant $(p<.05)$ at levels of relationship satisfaction $>5$ ]. For patients less satisfied with their relationships (lower $20 \%$ percentiles of the distribution), however, no significant simple slope emerged for the chosen conditional value of the moderator [low relationship satisfaction: simple slope (SE) $=-15.80$ (9.66), $z=-1.64, p=.102$; significant $(p<.05)$ at levels of relationship satisfaction $<3]$. As for main effects of the remaining covariates, patients wearing an indwelling catheter performed less PFE than patients without catheter. This effect points to patients' compliance with the recommendations of urologists, as patients are instructed to avoid PFE when they wear a catheter. Unexpectedly, burden by incontinence was not uniquely related with PFE. Follow-up analyses not reported here, indicated that the linear time trend, closely related to the decline of incontinence, took over some of the variance that is explained by the burden of incontinence effect when the time trend is not included.

The next models tested positive and negative affect variables as outcomes (see Table 2, Models 2 and 3). For patient-reported positive affect, again, a significant interaction between received spousal control and relationship satisfaction emerged. A plot (see Figure 1, Panel B) and simple-slope analyses indicated that for patients 
Table 2. Central Models Predicting Patients' Pelvic floor Exercise (Model 1), Positive Affect (Model 2) and Negative Affect (Model 3)

\begin{tabular}{|c|c|c|c|c|c|c|c|c|c|c|}
\hline & \multirow[b]{2}{*}{ Parameter } & \multicolumn{3}{|c|}{$\begin{array}{l}\text { Model 1: Pelvic floor } \\
\text { exercise }\end{array}$} & \multicolumn{3}{|c|}{$\begin{array}{c}\text { Model 2: Positive } \\
\text { affect }\end{array}$} & \multicolumn{3}{|c|}{$\begin{array}{c}\text { Model 3: Negative } \\
\text { affect }\end{array}$} \\
\hline & & Estimate & $S E$ & $p$ & Estimate & $S E$ & $p$ & Estimate & $S E$ & $p$ \\
\hline Intercept & $\gamma_{00}$ & 205.66 & 13.33 & $<.001$ & 2.40 & .05 & $<.001$ & 1.25 & .03 & $<.001$ \\
\hline TIME & $\gamma_{10}$ & -2.02 & .42 & $<.001$ & .001 & .001 & .968 & .001 & .001 & .481 \\
\hline Catheter & $\gamma_{20}$ & -213.69 & 26.97 & $<.001$ & -.09 & .08 & .259 & .12 & .05 & .019 \\
\hline Burden by incontinence & $\gamma_{30}$ & 3.82 & 2.75 & .169 & -.03 & .01 & .002 & .020 & .004 & $<.001$ \\
\hline Received spousal control & $\gamma_{40}$ & 4.49 & 7.59 & .561 & -.03 & .02 & .174 & .02 & .01 & .207 \\
\hline Relationship satisfaction & $\gamma_{50}$ & 1.97 & 9.43 & .835 & .10 & .04 & .006 & -.07 & .02 & $<.001$ \\
\hline Received spousal control * relationship satisfaction & $\gamma_{60}$ & 14.78 & 6.63 & .027 & .06 & .03 & .028 & -.02 & .01 & .199 \\
\hline
\end{tabular}

Note. $N=109$. $S E$ : standard error. Findings are based on 5 imputed data sets. Model 1: Random effect variances: intercept $\sigma_{0}^{2}(S E)=3167.82(1969.51)$; burden by incontinence $\sigma_{3}^{2}(S E)=120.88(85.85)$; Level 1 residual variance $\sigma^{2}(S E)=15914.19(2406.42) ; \rho(S E)=0.31(0.11)$. Pseudo $R^{2}=.27$. Model 2: Random effect variances: intercept $\sigma_{0}^{2}(S E)=0.14(0.02)$; relationship satisfaction $\sigma_{5}^{2}(S E)=0.02(0.02) ;$ TIME $\sigma_{1}^{2}(S E)=0.00002(0.00002)$. Level 1 residual variance $\sigma^{2}(S E)=0.13(0.02) ; \rho$ $(S E)=.015(0.10)$. Pseudo $R^{2}=.08$. Model 3: Random effect variances: intercept $\sigma_{0}^{2}(S E)=0.05(0.01)$; TIME $\sigma_{1}^{2}(S E)=0.000006(0.000005)$. Level 1 residual variance $\sigma^{2}(S E)=0.04(0.01) ; \rho(S E)=.16(0.09)$. Pseudo $R^{2}=.14$. 
Panel A

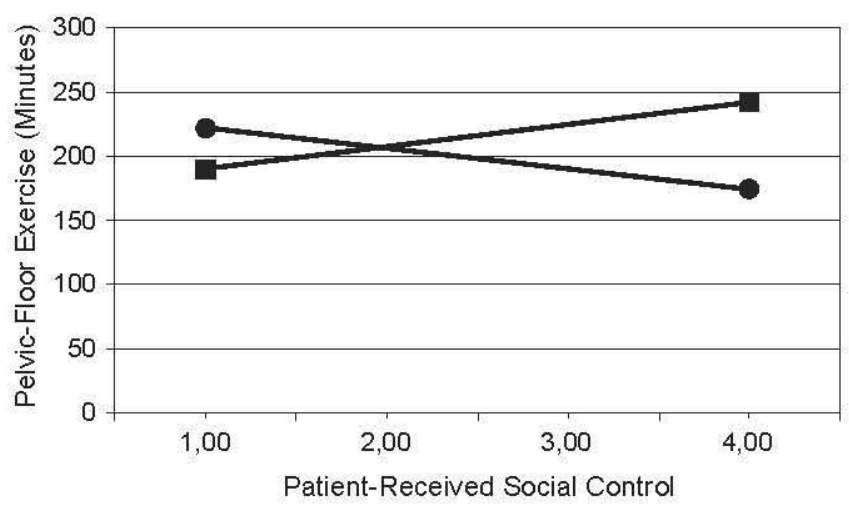

Relationship Satisfaction Low - Relationship Satisfaction High

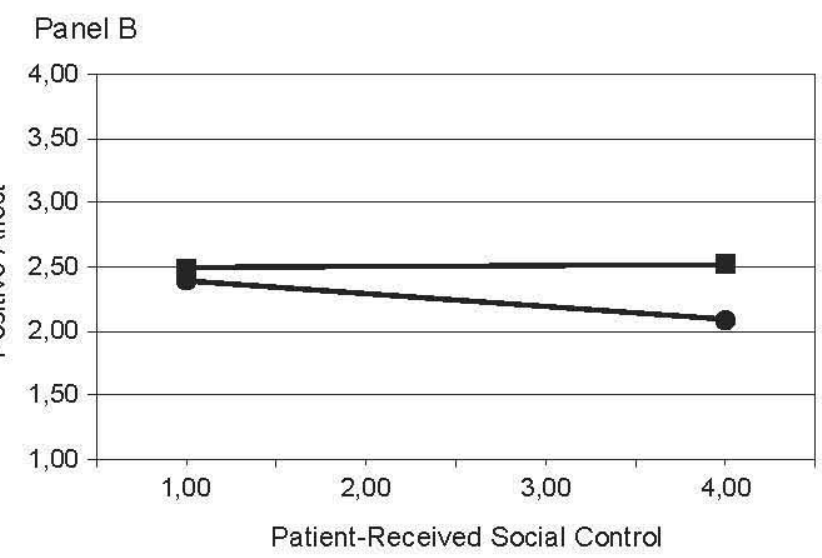

Relationship Satisfaction Low

Relationship Satisfaction High

Figure 1. Plotted interactions between patient reported received spousal control regarding PFE and patient reported relationship satisfaction predicting (Panel A) patients' PFE and (Panel B) patients' positive affect.

who were very happy with their relationships (upper $20 \%$ percentiles of the distribution), receipt of spousal control was not related with positive affect [high relationship satisfaction: simple slope $(\mathrm{SE})=.01(.02), z=.50, p=.618$; significant $(p<.05)$ at levels of relationship satisfaction $>6$, i.e., not within the range of the scale]. For patients less happy with their relationships (lower $20 \%$ percentiles of the distribution), on the other hand, received spousal control was negatively related with positive affect [simple slope $(\mathrm{SE})=-.11(.03), z=-3.18, p=.002$; significant $(p<.05)$ at levels of relationship satisfaction $<5]$. As a covariate, burden by incontinence was uniquely associated with lower levels of positive affect.

When we tested patients' negative affect as an outcome, contrary to our hypothesis, no significant interaction between received spousal support and relationship satisfaction emerged (see Table 2). However, main effects indicated positive 
unique relationships of burden by incontinence and presence of an indwelling catheter with higher negative affect reported by patients. Likewise, higher relationship satisfaction was independently associated with lower levels of negative affect.

\section{Discussion}

Results of this study indicate that the dual-effects model of social control may have to be extended to include characteristics of the control dyads' relationships as moderators (Okun et al., 2007; Tucker, 2002). Specifically, we found that social control received from the partner may support recipients' health behavior only when recipients are highly satisfied with their relationships. As such, prostate-cancer patients who were very happy with their relationships performed more PFE when partners specifically prompted or controlled them to do so. Moreover, these patients' concurrent positive affect levels were not related and thus apparently unharmed by received social control from their partners. On the other side, while social control received from partners was not predictive of PFE in patients less happy with their relationships, it was related to lower levels of concurrent positive affect. Thus, enriching the dual-effects model of social control by relationship satisfaction as a moderator could help resolve some of the conflicting evidence surrounding effects of social control (Tucker, 2002).

Several potential mechanisms of this pattern of findings are conceivable. One mechanism that has been proposed by Lewis and Butterfield (2005) includes attributions. Patients from more rewarding relationships might have tended to attribute more positive motives to their partners' controlling behavior than patients from less happy relationships. Positive attributions could include concern for the control recipients' well-being as a reason for partners' exerting control. More positive attributions for partners' behavior in more satisfactory relationships are also in accord with findings pointing to more positive sentiment override in happy relationships (e.g., Story et al., 2007). That is, happy partners tend to overestimate the positivity in partner interaction when compared to observational coding outcomes. On the other hand, receiving control from a partner within a less satisfactory relationship may cause the recipient to presume less prosocial motives such as, pleasure to manhandle or mistrusting the recipients' competences (Fincham, Beach, \& Nelson, 1987). In sum, attributions as to the motives of the partner's controlling behavior should shed further light on the role of relationship satisfaction as a moderator between spousal control and outcomes.

Further mechanisms that might explain the present findings are qualitative differences in the manner the "provider" exerts control on the recipient. In this study, we only looked at the frequency with which the partner tried to influence the patient to regularly perform PFE, however, we did not differentiate between positive and negative control strategies. A number of authors suggest this as a useful distinction (Okun et al., 2007; Tucker et al., 2006) and relate higher relationship quality and concomitant use of positive control strategies with more beneficial outcomes (Okun et al., 2007). Positive control strategies entail benign strategies such as, friendly persuasion or expression of positive emotions, however, they are conceptually hard to delineate from social support in that they may be indirectly supportive by rewarding desired behavior. With negative social control behaviors, on the other hand, network members exert pressure on a target person to exhibit the desired 
health behavior. By using overall received spousal control regarding PFE, we likely confounded positive and negative aspects of spousal control strategies. However, neither social control nor its interaction with relationship satisfaction was reliably associated with negative affect. This again could indicate that our measure of general spousal control may have captured predominantly positive received control as reported by patients. Positive couple interactions usually outnumber negative couple interactions (Lewis \& Butterfield, 2007), whereas negative dyadic interactions seem to be remembered more easily (Gable, Reis, \& Downey, 2003). Moreover, Okun et al. (2007) suggest and find indications for domain specificity with regard to positive and negative control strategies in terms of their relations with the respective affect variables. As in patients with less happy relationships, we found patient-received spousal control related with positive, but not negative affect, this might indirectly support the notion of predominance of positive control captured in our measure.

Additional findings indicated that spousal control was more frequent when patients' incontinence was still fairly strong, but subsided during patients' rehabilitation. This may point to need-based provision of social control from spouses. When patients' burden by incontinence was high, more control was exerted. This is in line with assumptions by Clark et al. (e.g., Clark \& Mills, 1993) who suggest that social exchange processes in communal or more intimate relationships follow a need-based pattern. While communal orientation usually refers to positive social exchange or exchange of benefits, it may extend to potentially less rewarding exchange, such as social control.

Finally, our findings indicate that patients' incontinence interfered with their emotional well-being following surgery. While this is not particularly surprising, there is a lack of quantitative research directly documenting such relationships. In most longitudinal studies, authors provide mean developments of incontinence and indicators of quality of life in the aftermath of prostate-cancer treatment, yet they do not provide statistical tests of the association (cf. Stanford et al., 2000). Our data show that higher burden by incontinence, i.e., stronger limitations in everyday life, was associated with more concurrent negative affect as well as less concurrent positive affect in patients. Considering that our analyses tested a series of concurrent associations over 12 months postsurgery, however, caution with regard to the direction of these associations is in order. An alternative interpretation of findings might place affect first. Worse affect may then enhance perceived everyday functional limitations caused by incontinence (Kendel et al., 2010).

\section{Limitations and outlook}

Important limitations of this study include the one-item assessments of central predictors and covariates. According to classical test theory, single-item assessments may result in problems with reliability possibly contributing to underestimation of effects. On the other hand, they might also lead to an enhanced risk of producing false positive results due to outlying ratings. To control the latter, we routinely checked the distribution of the level-1 residuals in our models and also searched for outliers. While residual distributions approached normality and outliers did not influence our central findings, we cannot rule out other faults of single-item assessments (e.g., Gardner, Cummings, Dunham, \& Pierce, 1998). 
Another limitation pertains to a failure to test lagged effects which does not allow insight into direction of associations. The present design prevented us from testing lagged effects as assessments were unequally spaced. In addition, inter-measurement intervals covered up to six months, making inferences about routine spousal control and its effects difficult. To capture more representative insights into couple exchange processes and test lagged effects thereof, a daily diary design would be preferable (Laurenceau \& Bolger, 2005).

Effects of spousal control in this study may be atypical in other respects also, as the target behavior investigated can be performed covertly, while attending to other daily activities. Therefore, the partner usually cannot tell whether or not the desired behavior was carried out which again might affect within-couple social control dynamics. Future work might contrast effects of spousal control regarding covert versus more obvious behavior.

Relatedly, assessments of central predictors and outcomes are based on selfreport only. In theory, measurement of received control from the partner as well as relationship satisfaction should be most valid when assessed via self-report as they entail patients' subjective appraisals that are difficult to quantify from other data sources, such as observations of couple interaction. On the other hand, self-reports can be biased by a number of factors, including social desirability, which we did not control in this study. Moreover, strength of pelvic-floor muscles can be objectively quantified for instance by using rectally inserted biofeedback devices that measure strength of pelvic-floor contractions. To minimize patients' burden associated with study participation, however, only self-reports of PFE were assessed. Consequently, we cannot rule out that our assessments were somewhat biased. Future work may apply multi-method approaches or correct for most prominent sources of bias.

Finally, future studies might shed some light on the specific mechanisms that further explain the connection between received social control and health-behavior change in recipients who are satisfied with their relationships to the control provider. For instance, social control might contribute to the recipients' self-regulatory processes that help to translate intentions into behavior. These could include more intense self-monitoring of the behavior to detect deviations from set goal standards (Carver \& Scheier, 2002), among others.

\section{Conclusions}

By way of its postsurgical sequelae, including urinary incontinence, RP challenges patients' functional capacity and mood. Findings suggest that implementation of regular PFE to control incontinence is supported by spousal control, but only in patients satisfied with their intimate relationships. Furthermore, these patients' affect seemed unharmed by received spousal control, whereas lower positive affect was a correlate of received control in patients with less happy relationships. Results thus indicate the utility of the inclusion of relationship quality as a moderator of the dualeffects model of social control.

\section{Note}

1. Data from this research project with prostatectomy patients and their partners have been published before. Parts of the data analyzed in the present paper were also used in work by 
Burkert et al. (forthcoming) and concerned patient reported PFE at two weeks and six months postsurgery. Furthermore, Knoll et al. (in press) used patients' affect and relationship satisfaction ratings at all measurement points in time in an article on predictors of partners' support provision following surgery. Finally, Knoll et al. (2009) used patients' ratings of relationship satisfaction at 12 months postsurgery as a dependent variable in a paper on predictors of patients' relationship satisfaction and erectile functions following RP. Thus, although there is some overlap with the variables used in the present paper, this paper presents the investigation of unique research questions not yet covered by previous publications from this project.

\section{References}

Benoit, M., Bouthillier, D., Moss, E., Rousseau, C., \& Brunet, A. (2010). Emotion regulation strategies as mediators of the association between level of attachment security and PTSD symptoms following trauma in adulthood. Anxiety, Stress \& Coping: An International Journal, 23, 101-118. doi:10.1080/10615800802638279

Berkman, L. F., Glass, T., Brisette, I., \& Seeman, T. E. (2000). From social integration to health: Durkheim in the new millennium. Social Science and Medicine, 51, 843-857. doi: $10.1016 / \mathrm{S} 02779536(00) 000654$

Burkert, S., Scholz, U., Gralla, O., \& Knoll, N. (forthcoming). Dyadic planning as a social and self regulatory strategy for health behavior change: A randomized controlled planning intervention. Manuscript submitted for publication.

Carver, C. S., \& Scheier, M. F. (2002). Control processes and self organization as complementary principles underlying behavior. Personality and Social Psychology Review, 6, 304-315. doi: $10.1207 / \mathrm{S} 15327957$ PSPR0604 05

Clark, M. S., \& Mills, J. (1993). The difference between communal and exchange relation ships: What it is and is not. Personality and Social Psychology Bulletin, 19, 684-691. doi: $10.1177 / 0146167293196003$

Coyne, J. C., Rohrbaugh, M. J., Shoham, V., Sonnega, J. S., Nicklas, J. M., \& Cranford, J.A. (2001). Prognostic importance of marital quality for survival of congestive heart failure, American Journal of Cardiology, 88, 526-529. doi:10.1016/S0002 9149(01)01731 3

European Association of Urology (EAU) (2010). Guidelines on prostate cancer. Retrieved from: http://www.uroweb.org/gls/pdf/Prostate $\% 20$ Cancer $\% 202010 \% 20 \mathrm{June} \% 2017$ th.pdf

Filocamo, M. T., Li Marzi, V., Del Popolo, G., Ceconi, F., Marzococo, M., Tosto, A., \& Nicita, G. (2005). Effectiveness of early pelvic floor rehabilitation treatment for post prostatectomy incontinence. European Urology, 48, 734-738. doi:10.1016/j.eururo.2005.06.004

Fincham, F. D., Beach, S R., \& Nelson, G. (1987). Attribution processes in distressed and nondistressed couples: III. Causal and responsibility attributions for spouse behavior. Cognitive Theory and Research, 11, 71-86. doi:10.1007/BF01183133

Gable, S. L., Reis, H. T., \& Downey, G. (2003). HE SAID, SHE SAID: A quasi signal detection analysis of daily interactions between close relationship partners. Psychological Science, 14, 100-105. doi:10.1111/14679280.t01 101426

Gardner, D. G., Cummings, L. L., Dunham, R. B., \& Pierce, J. L. (1998). Single item versus multiple item meausrement scales: an empricial comparison. Educational and Psychological Measurement, 58, 898-915. doi : 10.1177/0013164498058006003

Hahlweg, K. (1996). Fragebogen zur Partnerschaftsdiagnostik [Relationship Questionnaire]. Göttingen: Hogrefe.

Hahlweg, K., Klann, N., \& Hank, G. (1992). Zur Erfassung der Ehequalität: Ein Vergleich der'Dyadic Adjustment Scale' (DAS) und des'Partnerschaftsfragebogens' (PFB) [Assess ment of marital quality: A comparison of the Dyadic Adjustment Scale (DAS) and the Partnership Questionnaire (PFB)]. Diagnostica, 38, 312-327.

Helgeson, V.S., Novak, S. A., Lepore, S. J., \& Eton, D. T. (2004). Spouses' social control efforts: Relations to health behavior and well being among men with prostate cancer. Journal of Social and Personal Relationships, 21, 53-68. doi:10.1177/0265407504039840

Hughes, M., \& Gove, W. R. (1981). Living alone, social integration, and mental health. American Journal of Sociology, 87, 48-74. 
Karantanis, E., Fynes, M., Moore, K. H., \& Stanton, S. L. (2004). Comparison of the ICIQ SF and 24 hour pad test with other measures for evaluating the severity of urodynamic stress incontinence. International Urogynecological Journal and Pelvic Floor Dysfunction, 15, 111-116. doi: $10.1007 / \mathrm{s} 0019200411232$

Kendel, F., Gelbrich, G., Wirtz, M., Lehmkuhl, E., Knoll, N., Hetzer, R., \& Regitz Zagrosek, V. (2010). Predictive relationship between depression and physical functioning after coronary surgery. Archives of Internal Medicine, 170, 1717-1721.

Knoll, N., Burkert, S., Kramer, J., Roigas, J., \& Gralla, O. (2009). Relationship satisfaction and erectile functions in men receiving laparoscopic radical prostatectomy: Effects of provision and receipt of spousal social support. Journal of Sexual Medicine, 6, 1438-1450. doi: $10.1111 / \mathrm{j} .1743$ 6109.2009.01244.x

Knoll, N., Burkert, S., Luszczynska, A., Roigas, J., \& Gralla, O. (in press). Predictors of spousal support provision: A study with couples adapting to incontinence following radical prostatectomy. British Journal of Health Psychology.

Knoll, N., Rieckmann, N., \& Kienle, R. (2007). The other way around: Health as a predictor of perceived social support. Anxiety, Stress and Coping, 20, 3-16. doi:10.1080/ 10615800601032823

Krohne, H. W., Egloff, B., Kohlmann, C. W., \& Tausch, A. (1996). Untersuchungen mit einer deutschen Form der Positive and Negative Affect Schedule (PANAS). Diagnostica, 42, $139-156$.

Kurdek, L. A. (2004). Are gay and lesbian cohabiting couples really different from heterosexual married couples? Journal of Marriage and the Family, 66, 880-900. doi: $10.1111 /$ j.0022 2445.2004.00060.x

Laurenceau, J. P., \& Bolger, N. (2005). Using diary methods to study marital and family processes. Journal of Family Psychology, 19, 86-97. doi:10.1037/0893 3200.19.1.86

Lewis, M. A., \& Butterfield, R. M. (2005). Antecedents and reactions to health related social control. Personality and Social Psychology Bulletin, 31, 416-427. doi:10.1177/0146 167204271600

Lewis, M. A., \& Butterfield, R. M. (2007). Social control in marital relationships: Effect of one's partner on health behaviors. Journal of Applied Social Psychology, 37, 298-319. doi:10.1111/j.0021 9029.2007.00161.x

Lewis, M. A., \& Rook, K. S. (1999). Social control in personal relationships: Impact on health behaviors and psychological distress. Health Psychology, 18, 63-71. doi:10.1037/0278 6133.18.1.63

Okun, M. A., Huff, B. P., August, K. J., \& Rook, K. S. (2007). Testing hypotheses distilled from four models of the effects of health related social control. Basic and Applied Social Psychology, 29, 185-193. doi:10.1080/01973530701332245

Preacher, K. J., Curran, P. J., \& Bauer, D. J. (2006). Computational tools for probing interaction effects in multiple linear regression, multilevel modeling, and latent curve analysis. Journal of Educational and Behavioral Statistics, 31, 437-448. doi:10.3102/ 10769986031004437

Resendes, L. A., \& McCorkle, R. (2006). Spousal responses to prostate cancer: an integrative review. Cancer Investigation, 24, 192-198. doi:10.1080/07357900500524652

Robert Koch Institute (RKI) and Society of Epidemiologic Cancer Registers in Germany (2010). Krebs in Deutschland 2005/2006: Häufigkeiten und Trends [Cancer in Germany: Frequencies and trends]. Retrieved from: http://www.ekr.med.uni erlangen.de/GEKID/ Doc/KID2010.pdf

Rook, K. S., \& Ituarte, P. H. G. (1999). Social control, social support, and companionship in older adults' family relationships and friendships. Personal Relationships, 6, 199-211. doi:10.1111/j.1475 6811.1999.tb00187.x

Rook, K. S., Thuras, P. D., \& Lewis, M. A. (1990). Social control, health risk taking, and psychological distress among the elderly. Psychology and Aging, 5, 327-334. doi:10.1037/ 08827974.5 .3 .327

Schafer, J. L. (1999). NORM: Multiple imputation of incomplete multivariate data under a normal model, version 2. Software for Windows 95/98/NT. Retrieved January 2, 2003, from http://www.stat.psu.edu/ jls/misoftwa.html. 
Scholz, U., Knoll, N., Roigas, J., \& Gralla, O. (2008). Effects of provision and receipt of social support on adjustment to laparoscopic radical prostatectomy. Anxiety, Stress, \& Coping, 21, 227-241. doi:10.1080/10615800801983759

Spanier, G. B. (1976). Measuring dyadic adjustment: New scales for assessing the quality of marriage and similar dyads. Journal of Marriage and the Family, 38, 15-28. doi: 10.2307/ 350547

Stanford, J. L., Feng, Z., Hamilton, A. S., Gilliland, F. D., Stephenson, R. A., Eley, J. W., ... \& Potosky, A. L. (2000). Urinary and sexual function after radical prostatectomy for clinically localized prostate cancer: The Prostate Cancer Outcomes Study. Journal of the American Medical Association, 283, 354-360. doi:10.1001/jama.283.3.354

Stephens, M. A. P., Rook, K. S., Franks, M. M., Khan, C., \& Iida, M. (2010). Spouses use of social control to improve diabetic patients' dietary adherence. Families, Systems and Health, 28, 199-208. doi:10.1037/a0020513

Story, T. N., Berg, C. A., Smith, T. W., Beveridge, R., Henry, N. J. M., \& Pearce, G. (2007). Age, marital satisfaction, and optimism as predictors of positive sentiment override in middle aged and older married couples. Psychology and Aging, 22, 719-727. doi:10.1037/ 0882 7974.22.4.719

Thorpe, C. T., Lewis, M. A., \& Sterba, K. R. (2008). Reactions to health related social control in young adults with type 1 diabetes. Journal of Behavioral Medicine, 31, 93-103. doi: $10.1007 / \mathrm{s} 1086500791254$

Tucker, J. S. (2002). Health related social control within older adults' relationships. The Journals of Gerontology: Series B: Psychological Sciences and Social Sciences, 57B, 387-395.

Tucker, J. S., Orlando, M., Elliott, M. N., \& Klein, D. J. (2006). Affective and behavioral response to health related social control. Health Psychology, 25, 715-722. doi:10.1037/0278 6133.25.6.715

Umberson, D. (1992). Gender, marital status and the social control of health behavior. Social Science \& Medicine, 34, 907-917. doi:10.1016/0277 9536(92)90259 S

Watson, D., Clark, L. A., \& Tellegen, A. (1988). Development and validation of brief measures of positive and negative affect: The PANAS scales. Journal of Personality and Social Psychology, 54, 1063-1070. doi:10.1037/0022 3514.54.6.1063 